\title{
Accident analysis of large-scale techno- logical disasters applied to an anaesthetic complication
}

The occurrence of serious accidents in complex industrial systems such as at Three Mile Island and Bhopal has prompted development of new models of causation and investigation of disasters. These analytical models have potential relevance in anaesthesia. We therefore applied one of the previously described systems to the investigation of an anaesthetic accident. The model chosen describes two kinds of failures, both of which must be sought. The first group, active failures, consists of mistakes made by practitioners in the provision of care. The second group, latent failures, represents flaws in the administrative and productive system. The model emphasizes the search for latent failures and shows that prevention of active failures alone is insufficient to avoid further accidents if latent failures persist unchanged. These key features and the utility of this model are illustrated by application to a case of aspiration of gastric contents. While four active failures were recognized, an equal number of latent failures also became apparent. The identification of both types of failures permitted the formulation of recommendations to avoid further occurrences. Thus this model of accident causation can provide a useful mechanism to investigate and possibly prevent anaesthetic accidents.

La survenue d'une série d'accidents dans des complexes industriels tels que Three Mile Island et Bhopal ont déclenché le développement de nouvelles méthodes de causalité et d'investigation de désastres. Ces modeles analytiques sont potentiel-

\section{Key words}

COMPLICATIONS: accidents.

From the ${ }^{1}$ Department of Anaesthesia, Foothills Hospital at the University of Calgary, Calgary, Alberta, Canada and ${ }^{2}$ Department of Psychology, University of Manchester, Manchester, U.K.

Address correspondence to: Dr. C.J. Eagle, Department of Anaesthesia, Foothills Hospital, $1403-29$ St. N.W., Calgary, Alberta, T2N 2T9.

Accepted for publication 19th September, 1991.
Chris J. Eagle MD FRCPC, ${ }^{1}$

Jan M. Davies MSc MD FRCPC, ${ }^{1}$ J. Reason PhD ${ }^{2}$ lement intéressants en anesthésie. Ainsi, on a appliqué un des systèmes préalablement décrits afin d'étudier les accidents anesthésiques. Le modèle choisi décrit deux sortes d'échecs qui doivent tous les deux être recherchés. Le premier groupe, des échecs actifs, consiste en des erreurs que le practicien commet dans la pratique de sa profession. Le deuxième groupe, des échecs latents, représente des défauts dans les sytèmes administratifs et productifs. Le modèle met l'emphase sur la recherche des échecs latents et démontre que la prévention des échecs actifs seul n'est pas suffisant afin d'éviter des accidents futurs si les échecs latents demeurent inchangés. Ces critères de base et l'utilité de ce modèle sont illustrés par l'application dans un cas d'aspiration du contenu gastrique. Alors que quatre échecs actives furent reconnus, un nombre égal d'échecs latents est devenu apparent. L'identification des deux types d'échecs permet la formulation de recommandations afin d'éviter la répétition de ces échecs. Ainsi, ce modèle d'investigation des causalités d'accidents peut fournir un mécanisme utile d'investigation et possiblement de prévention des accidents anesthésiques.

Recent large-scale technological disasters, such as the explosions at Three Mile Island and the Chemobyl nuclear power plants, the Bhopal pesticide plant, and the Challenger space shuttle, have given impetus to the development of better models of accident analysis. Concurrently, research in industrial psychology and human engineering has provided improved understanding of the ways in which practitioners may contribute to adverse outcome. ${ }^{1,2}$ These advances can be applied to anaesthetic practice to determine contributory causes of adverse events.

In the model illustrated in this article, accidents are seen to be the result of two different but complementary forms of failure, "active" and "latent." "The first type, "active failures," occurs at the interface between humans and the other components of the complex systems within which they work. In anaesthesia, active failures include problems arising from the anaesthetist's interaction with the patient or anaesthetic equipment, such as unrecognized oesophageal intubation or anaesthetic machine disconnection. The 
TABLE I Levels of organization and corresponding failures

\begin{tabular}{|c|c|c|c|c|}
\hline \multicolumn{2}{|c|}{ Productive level } & \multirow{2}{*}{$\begin{array}{l}\text { Anaesthetic analogue } \\
\text { Hospital administration }\end{array}$} & \multirow{2}{*}{$\begin{array}{l}\text { Types of failures } \\
\text { Management failure }\end{array}$} & \multirow{2}{*}{$\begin{array}{l}\text { Active or latent } \\
\text { Latent }\end{array}$} \\
\hline 1 & Decision-makers & & & \\
\hline 2 & Line management & Departmental administration & $\begin{array}{l}\text { Faulty policies and } \\
\text { procedures }\end{array}$ & Latent \\
\hline 3 & Preconditions & $\begin{array}{l}\text { Qualified staff, equipment which } \\
\text { meets current standards }\end{array}$ & $\begin{array}{l}\text { Lack of training and } \\
\text { equipment }\end{array}$ & Latent \\
\hline 4 & Productive activities & Administration of anaesthetics & Unsafe acts & Active \\
\hline & Defences & Quality assurance activities & $\begin{array}{l}\text { Failure to recognize } \\
\text { previous failures }\end{array}$ & Latent \\
\hline
\end{tabular}

TABLE II The three steps of accident investigation (adapted in part from Barnhart et al., 1975

\section{Step 1 - "When"}

Assembly of facts and generation of timeline

- include events before and after accident if appropriate

Step 2 - "What"

Identification of active failures

- description of all behaviours

- "function analysis"

Step 3 - "Why"

Identification of latent failures

- "information processing analysis"

- sources of information available (latent)

- what information perceived, used and in what ways

- which decisions made, listing all choices

- whether actions matched decisions (latent and active)

activities of the "front-line' operators" appear to be the "principal instigators of system breakdown." 2 However, their role is to provide many of the "local triggering conditions" 2 necessary to expose crucial weaknesses in the system (resulting from preexisting problems).

Whereas active failures have an immediate impact on the patient, the second type, "latent failures," may lie dormant in a system before their adverse consequences become apparent. Latent failures are not revealed until active failures occur; the interaction between the two types of error is necessary to produce a disaster. Latent failures represent problems with the design, construction or maintenance of equipment, computer sofware, and/or operational procedures, etc. Such problems may also exist with the organization of medical care at the level of operating rooms, department, or hospital (Table I). As Reason has stated, all complex organizations contain these latent failures which are analogous to the "resident pathogens" within a body and which, in combination with external factors (e.g., stress), cause disease. ${ }^{2}$ Increasing numbers, complexity, or strategic positioning of latent failures portend disaster. However, active failures may not all lead to disasters - they may be only relatively minor "tokens" of an underlying latent failure. "Unsafe acts" may not be recognised, not reported, or their significance not realized.

We present a case report of pulmonary aspiration of gastric contents to illustrate the principal features of this model.

\section{Methods}

Investigation of the cause of large-scale disasters involves three steps (Table II). First, facts are assembled and a "time line" 3 of events is generated. This step provides investigators with details of "when" things occurred. Second, active failures are identified. This step, known as "function analysis," requires the description of the behaviour of all personnel involved ${ }^{3}$ and provides the investigators with knowledge of "what" occurred. Third, examination and assessment is made of the contribution of latent failures. This step is an expansion of "information processing analysis," ${ }^{3}$ with emphasis on the role of deficiencies in the working system, and helps explain "why" the accident occurred. The investigation of anaesthetic accidents follows similarly.

Within $48 \mathrm{hr}$ of the anaesthetic accident in question, a meeting was held with all involved anaesthetic, surgical, and nursing staff. The purpose of the meeting (in accordance with the Department of Anaesthesia's Risk Management Protocol), ${ }^{4}$ was to clarify the course of events and to collect opinions about contributing factors. Subsequently, this information was organized chronologically, active failures identified and latent failures sought and assessed. Lastly, recommendations were made to help prevent future similar problems (Figure).

\section{Results}

\section{Case report}

A 72-yr-old white man was booked on the elective Operating Room (OR) schedule to have cystoscopy performed under local anaesthesia. Consequently, no anaesthetist assessed the patient before surgery. On the morning of the procedure, the attending urologist was unavailable due to 


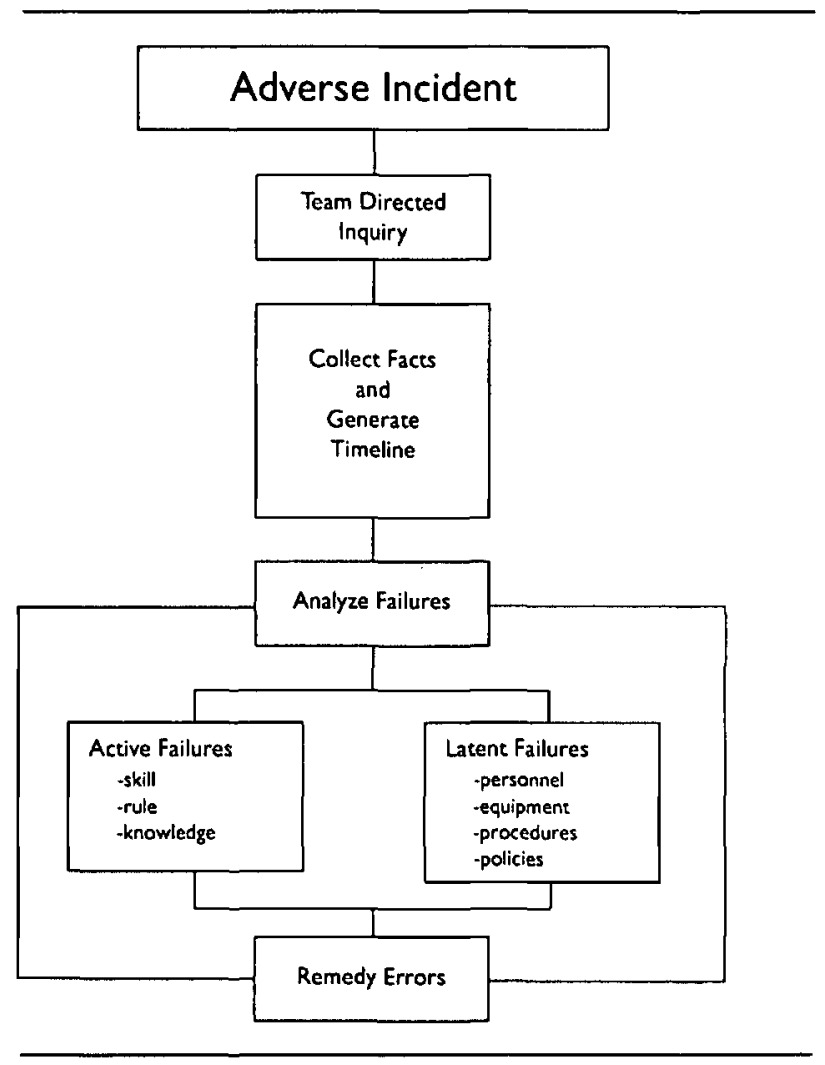

FIGURE A model of accident investigation.

an OR scheduling conflict. A surgical colleague, who had not seen the patient, was asked to perform the cystoscopy. He agreed but requested that the patient receive a general anaesthetic. The anaesthetic coordinator located an available anaesthetist. This anaesthetist was not informed of the original booking (under local anaesthesia) nor that the urologist was unfamiliar with the patient, and had the understanding that the case was an urgent addition to the Operating Room list.

When first seen by his anaesthetist in the operating room, the patient was found to be combatative, confused, and unable to give a history. The nursing notes showed that the patient had fasted for over $24 \mathrm{hr}$. Several problems were noted from the chart: (1) progressive deterioration in mental status; (2) metastatic cancer (lungs, liver) from an unknown primary tumor, and secondary hypercalcaemia (under treatment); (3) renal insufficiency; and (4) anaemia.

The patient vigorously resisted being moved to the cystoscopy table. The anaesthetist therefore elected to induce anaesthesia with the patient on his bed. Routine monitors (ECG, NIBP, $\mathrm{SaO}_{2}$ ) were applied. Thiopentone, $150 \mathrm{mg}$, and alfentanil, $500 \mu \mathrm{g}$, were administered intravenously. Following loss of consciousness, the patient regurgitated more than two litres of fluid and undigested food. The patient was immediately turned on his side and vomitus suctioned from his mouth. After tracheal intubation, the patient's lungs were ventilated with $100 \%$ oxygen, and intravenous fluids were administered. Fibreoptic bronchoscopy, performed within several minutes of aspiration, showed large volumes of fluid, but no particulate materials, in the patient's bronchi. The patient was transferred to the Intensive Care Unit. After consultation with the family, the patient was given only supportive care (hydration and sedation). He died six days later.

\section{Analysis}

After the event, the patient's chart was reviewed to provide an outline of key events and to determine if there was any indication of increased risk of regurgitation. An episode of "projectile vomiting" had occurred at 4 am on the morning of surgery. As a result of analysis, four active and four latent failures were found (Table III).

\section{ACTIVE FAILURES}

The initial booking made by the urologist for cystoscopy under local anaesthesia was an active error. By using the rule of thumb that "elderly patients presenting for cystoscopy are given local anaesthetics," the urologist selected the wrong form of anaesthetic for a confused, combative patient. Active failures were also made by the anaesthetist. The first of these was the decision to proceed with the case, despite having performed only a cursory assessment of a patient with numerous medical problems. Further, the possibility of a "full stomach" was discounted because the patient was apparently fasting (despite lack of patient confirmation). Finally, the illusion of having completed an accurate preoperative assessment encouraged the anaesthetist to proceed.

\section{LATENT FAILURES}

Latent failures also contributed to the problem. The $O R$ scheduling system inappropriately allowed a surgeon to be assigned to two different areas simultaneously. Lack of a formalized system of communication resulted in the anaesthetist's lack of awareness of the true urgency of the case and the last-minute substitution of another urologist. The change of anticipated anaesthetic allowed the patient to bypass the usual preoperative evaluation the evening before surgery. The episode of vomiting was recorded in a nurse's entry in the computerized record-keeping system, but was obtainable only in the computerized record system. No "hard copy" was attached to the chart sent to the OR and, in addition, no computer terminals were located in the $O R$. At the time of the incident, anaesthetists were unaware of the delay in producing hard copies of nursing records and the resultant serious lack of information in the patient chart. 
TABLE III Time line of events and classification according to type of failure (active or latent)

\begin{tabular}{|c|c|c|}
\hline Time & Event & $\begin{array}{l}\text { Failure } \\
\text { type }\end{array}$ \\
\hline 1800 & $\begin{array}{l}\text { Patient booked for local anaesthetic } \\
\text { No preoperative visit }\end{array}$ & $\begin{array}{l}\text { Active } \\
\text { Latent }\end{array}$ \\
\hline 2400 & Patient fasting & \\
\hline 0400 & $\begin{array}{l}\text { Episode of vomiting charted on computer } \\
\text { record }\end{array}$ & Latent \\
\hline 1000 & $\begin{array}{l}\text { Patient arrives in OR } \\
\text { Surgeon unavailable (double booked) } \\
\text { Second surgeon arrives } \\
\text { Second surgeon contacts anaesthetic } \\
\text { coordinator }\end{array}$ & Latent \\
\hline 1015 & $\begin{array}{l}\text { Coordinator locates an anaesthetist } \\
\text { Anaesthetist unaware an elective nature of } \\
\text { case and of substitution of surgeon }\end{array}$ & Latent \\
\hline 1020 & $\begin{array}{l}\text { Anaesthetist evaluates patient } \\
\text { - assumes fasting status correct } \\
\text { - assumes full data available on chart } \\
\text { - proceeds with anaesthetic on basis } \\
\text { of available information }\end{array}$ & $\begin{array}{l}\text { Active } \\
\text { Active } \\
\text { Active }\end{array}$ \\
\hline 1030 & Induction followed by aspiration & \\
\hline
\end{tabular}

\section{Discussion}

When accidents arise, careful investigation is required to identify the causal factors involved. Establishment of a timeline, or "temporal reconstruction of key events"5 is essential and often requires detailed examination of the record and other documents such as "narrative statements" by personnel involved. Information must be organized so that, as Caplan states, the retrieval of key pieces does not become "irksome and inefficient." Investigation of contributing causes must be done systematically ${ }^{5-7}$ working back from the active failures which precipitated the event through the latent failures which provided the conditions necessary for disaster. Further analysis and research may then be required to develop recommendations aimed at preventing recurrence of the event, the purpose of accident investigation. Thus, no matter how an accident is investigated or what the cause, all accidents should lead to the generation and implementation of recommendations to prevent further such occurrences. However, the remedial measures derived from the investigation must be soundly based or the process may be wasted.

Active failures have been the focus of attention in previous studies of anaesthetic mishaps. For example, Gaba described a schema of decision-making in anaesthesia, identifying the four levels at which an anaesthetist works and therefore at which things can go wrong: supervisory control, sensory/motor, procedural and abstract. ${ }^{8}$ Unfortunately, analysis only of active failures leads to a constrained view of the problem. Focussing on the anaes- thetist excludes the influence and interaction of, and latent failures extant in, other operating room personnel, the operating room environment, organization of the hospital, and local, regional and national health care practices.

In current anaesthetic practice, active failures continue to receive major, if not exclusive, attention and form the centre of discussion at traditional morbidity and mortality rounds. Frequently, the errant practitioner while explaining what he or she did "wrong" is cast in the role of the "bad apple." This has deleterious effects. First, other contributing causes of the accident go unnoticed. Second, as described by Berwick in his "Theory of Bad Apples,"9 practitioners may become fearful, defensive and uncooperative.

Thus, when planning strategies to prevent future accidents, remedial action must be directed at removing the latent failures as well as the active. The historical tendency to focus entirely on the operator allows underlying latent failures to remain. The ease with which an operator can be "blamed" refocuses the attention of highlevel decision-makers away from the need to acknowledge and address problems with corporate and organizational structure (which are usually more difficult to change). As illustrated above, the search for latent failures provides significant information which can help prevent similar events by identifying and eradicating or neutralizing "resident pathogens." For example, a significant latent failure in the case described above was that of less than optimal patterns of communication in the Operating Room, a factor which has been identified as causal to disaster by other authors. ${ }^{8,10}$

Because anaesthetic care is frequently provided in institutions which are large and have complex administrative structures, the dynamics of such "complex sociotechnical systems" 2 must be recognized. This interaction was described in the 1930's. "Problems, and therefore opportunities to improve quality, (have) usually been built directly into the complex production processes ... Defects in quality (can) only rarely be attributed to a lack of will, skill, or benign intention among the people involved with the processes." and systemic problems both in and beyond the Operating Room, the search for latent failures complements the acknowledgement of active failures. Such a procedure is essential to Quality Improvement programs, in which integrated analysis of effectiveness and efficiency follows patterns of patient care.

In summary, analysis of major disasters has produced a model which differentiates "practitioner" from "organizational" failures. We believe that this model provides a useful structure and nomenclature of the events and causal factors in anaesthetic mishaps and would recommend its application. 


\section{Acknowledgement}

The authors thank Dr. R.B. Lee, Director, Bureau of Air Safety Investigation, Canberra, Australia, for help in the preparation of this manuscript.

\section{References}

1 Reason J. Human Error. New York: Cambridge University Press, 1990.

2 Reason $J$. The contribution of latent human failures to the breakdown of complex systems. Phil Trans $R$ Soc Lond 1990; 327: 475-84.

3 Barnhart W, Billings $C$, Cooper $G$ et al. A method for the study of human factors in aircraft operations. Technical Memorandum, Report No. TM X-62,472, National Aeronautics and Space Administration, Washington, D.C., 1975.

4 Davies JM. On-site risk management. Can J Anaesth 1991; 38: 1029-30.

5 Caplan RA. In-depth analysis of anesthetic mishaps: tools and techniques. Int Anesthesiol Clin 1989; 27: 153-60.

6 Galletly DC, Mushet NN. Anaesthesia system errors. Anaesth Intensive Care 1991; 19: 66-73.

7 Davies JM, Armstrong JN, Lee RB. A systematic approach to the investigation of anaesthetic incidents. Anaesth Intensive Care 1991; 19: 285.

8 Gaba DM. Human error in anesthetic mishaps. Int Anesthesiol Clin 1989; 27: 137-47.

9 Berwick DM. Continuous improvement as an ideal in health care. N Engl J Med 1989; 320: 53-6.

10 Cooper JB, Newbower RS, Kitz RJ. Analysis of major errors and equipment failures in anesthesia management. Anesthesiology 1984; 60: 34-42. 